\title{
Sobre Influencias en la Novela Guatemalteca
}

\begin{abstract}
$\mathrm{A}^{4}$ LA vez que la novela guatemalteca, así como las otras novelas hispanoamericanas, ha seguido el proceso histórico de los distintos movimientos literarios, ha recibido también diversas influencias, de las cuales no hay duda que la española es la más preponderante. Como los guatemaltecos no tuvieron que levantarse en armas contra la madre patria para conseguir su independencia, no conocían aquellos arrebatos violentos contra toda la herencia española que llevaron al célebre Sarmiento al punto de abogar por la creación de un nuevo idioma americano. Una parte integral de la instrucción guatemalteca siempre ha sido el estudio de la literatura española y, sobre todo, la del Siglo de Oro, cuya huella se observa en la novela, desde Irisarri hasta la actualidad. Aunque la Historia del perínclito Epaminondas del Cauca no es propiamente una novela, delata la influencia de la picaresca española en las condiciones humildes de los padres del protagonista y en el artificio de un rápido cambio de amos, que permtie al autor comentar los sucesos y las condiciones de su época. El estilo ingenioso de Irisarri es algo exagerado pero tiene, de todos modos, parentesco con el de los mejores hablistas del barroco ${ }_{2}$ inclusive Cervantes y Quevedo. Sucesor de Irisarri y verdadero fundador de la novela guatemalteca, José Milla también da testimonio de la fuerza inspiradora de la picaresca en su "novela galopante" El esclavo de don Dinero. El hecho de que Hondura (1947) de Arévalo Martínez y Un personaje sin novela (I958) de David Vela comiencen con la narración de los primeros años desgraciados del pícaro protagonista antes de tomar por otios rumbos atestigua lo inagotable que es el tema. Aunque la influencia de la picaresca española es innegable, sería difícil señalar la fuente exacta de cierto episodio o de cierto
\end{abstract}


personaje, es decir, se trata de una influencia más inspiradora que precisa.

En cambio, Don Quijote influyó de una manera muy concreta desde el nacimiento de la novela guatemalteca hasta su madurez. El Visitador, la mejor novela histórica de Milla, contiene escenas inspiradas directamente en el Cuento del curioso impertinsante, y en el "vuelo" de Cla. vileño, en los latigazos que Santo había de darse para desencantar a Dulcinea y en la transformación de Sancho en gobernador de la ínsula Barataria. El aspecto popular representado por Sancho y el ventero también fueron utilizados por Milla para dar más gracia a su obra. Varios capítulos suyos llevan títulos al estilo de los del Quijole sin que todo eso altere el espíritu netamente guatemalteco de la obra. El material episódico del Quijote vuelve a aparecer en otra novela histórica. Don Juan Núñez García de Agustín Mencos Franco en una adaptación de la primera salida del Caballero de la Triste Figura y de las necesidades fisiológicas que sintió Sancho Panza. En el siglo veinte, el predominio del Quijote se percibe claramente en Semilla de mostaza de Elisa Hall que contiene una historia morisca, un cuento italiano, un escrutinio de libros, un palacio como el de los duques, el empleo de los disfraces y, otra vez, las necesidades fisiológicas de un personaje sanchesco.

Aunque Dion Quijote ha gozado de gran poularidad entre los autores guatemaltecos, hay otras obras que influyeron con más fuerza la concepción básica de sus novelas. Las de José Milla, Agustín Mencos Franco y J. Fernando Juárez Muñoz, por muchos episodios cervantinos que incluyan, tienen mayor deuda con el teatro barroco y romántico. Toda su fórmula melodramática se deriva, en general, de las comedias de capa y espada y de sus continuadores románticos. Sin querer indicar una actuación particular del Don Alvaro, veamos los rasgos que tiene en común con las novelas millescas: un amor imposible; el origen del protagonista envuelto en un misterio, cuya explicación depende sólo de unos papeles secretos; una mujer disfrazada de hombre; cambio de los nombres de dos personajes; escape milagroso de la muerte, seguido, luego, de un duelo; refugio de los respectivos protagonistas en un monasterio y en una "ermita" y la unión de personajes aristocráticos con plibeyos dentro de la misma obra.

Los autores españoles más modernos también han ejercido su influencia. Para representar la lucha entre liberales y conservadores, el 
doctor Salazar se inspiró, por entero ${ }_{2}$ en dos obras del reformador liberal Benito Pérez Galdós. Conficictos es la versión guatemalteca de una combinación de Doña Perfecta y de La familia de León Roch. Cuarenta años más tarde, todavía no se habían resuelto los aspectos fundamentales de ese problema y la Orbajosa de Doña Pierfecta resucita en la igualmente conservadora e hipócrita Ficciona de Paulita de César Brañas. Una situación familiar - la reacción violenta de un muchacho enfermizo contra el novio de su hermana mayor- en otra novela de Brañas, Un bombre solo, tiene sus raices en Torquemada en la cruz. El único novelista es. pañol del siglo veinte que ha tenido una acción decisiva en Guatemala es Valle-Inclán. Sor Candelaria de César Brañas revela el mismo espíritu decadentista de Sonata de primavera en tanto que Las memorias intimas del Visconde de Esperia de Drago Bracco es una imitación innegable pero bien escrita de esta misma obra.

Aunque París fue el centro literario del siglo diez y nueve y ha seguido desempeñando un papel importante en el siglo veinte, en la novela hispanoamericana no ha predominado tanto como se creería. En Guatemala, las obras francesas, correspondientes a los tres últimos siglos, acusan sólo una influencia de carácter general. Las novelas filosóficas de Voltaire podrían ser las fuentes de la Historia del perinclito Epami. nondas del Cauca; pero Irisarri conocía muchas obras de los enciclopedistas franceses y aunque compartía con Voltaire un espíritu mordaz, era muy vagabundo para poder sujetar sus ideas a la forma concisa de un Candide. En cuanto al romanticismo francés, sólo en dos novelas poco conocidas se observan sus trazas. Edmundo de José A. Beteta exhala el mismo espíritu liberal y humanitario que Los miserables de Victor Hugo, mientras que Fernando Pineda no tiene inconveniente en dejar leer al protagonista de Luis las novelas sentimentales de Bernardin de SaintPierre, Chateaubriand y Lamartine. Aunque Pineda captó el hálito de las obras francesas, Francisco Lainfiesta tiene una deuda más directa con Jules Verne respecto a las invenciones fantásticas, que sin embargo, no constituyen más que una parte secundaria de $A$ vistá de pájaro. Por encima del contacto con Verne, se destacan la gran originalidad y la actitud crítica de Lainfiesta. El naturalismo de Martínez Sobral desciende directamente de la pluma de Zola, pero sus obras no incluyen ningún episodio ni personaje sacado directamente de la serie de Rougon-Macquart. Aun Enrique Gómez Carrillo, el más afrancesado de todos, sólo se dejó influir de manera general por La vida de Bobemia de Henri 
Murger. Los temas, el espíritu y hasta el estilo de las Tres noveles inmorales surgieron de la obra francesa, pero los argumentos son originales. En cuanto al siglo veinte, el existencialismo de Sartre es responsable en parte por la angustia de Una manera de morir de Mario Monteforte Toledo. Es que tanto las obras de Sartre como las de Voltaire, de Hugo y de Zola se conocen por todo el mundo y por eso no han podido menos de influir en la novela guatemalteca. No obstante, cabe afirmar que esa influencia era menos íntima que la de España.

La literatura de otros países europeos y la de los Estados Unidos, por importante el papel que le haya correspondido en casos particulares, no se conoce tanto como la de España y Francia. De la misma manera general como Zola influyó en las obras naturalistas de Martínez Sobral, Walter Scott influyó en las novelas históricas de José Milla. El propio Milla es uno de los pocos autores hispanoamericanos que se sintió atraído por Dickens, lo cual se revela en la concepción de algunos capítulos y varios detalles de Memorias de un abogado y de Historia de un pepe. Otro punto de contacto con la literatura inglesa es la relación entre Los vidjes de Gulliver de Jonathan Swift y las interpretaciones fantásticas que presentó Arévalo Martínez en El mundo de los mabarachias y en Viaje a Ipanda sobre las relaciones internacionales inmediatamente antes de la Segunda Guerra Mundial.

En cuanto a Italia, algunos críticos han señalado un parentesco entre las novelas históricas de Milla y Los novios de Manzoni, pero, en realidad, sería muy difícil de comprobar. En cambio, Farándula sentimental de Drago Bracco parece directamente inspirada en la Commedia dell' Arte y los tres finales posibles de Un personaje sin novela de David Vela tiene sus antecedentes en Pirandello.

El único novelista portugués que ha penetrado en el mundo hispanoamericano es Eça de Queiroz. César Brañas, en su primera novela Alba Emérita, da testimonio de haber leído $O$ crime do padre Amaro en su presentación de la figura del cura lascivo. Sólo el doctor Ramón A. Salazar se sintió tentado por la literatura alemana y a ella se atribuye lo fantástico que hay en Stellat. A pesar de la gran importancia de los novelistas rusos del siglo diez y nueve, no hay ninguna huella de ellos en la novela guatemalteca. Es que además de las diferencias básicas entre los dos países, las novelas de Tolstoy y Dostoyevsky se publicaron antes de que los novelistas guatemaltecos hubieran alcanzado la madurez 
necesaria para apreciarlas. En cambio, últimamente Donde acaban los caminos (1953) de Monteforte y La volanda (1956) de Arqueles Vela han demostrado bastante madurez para absorber la complicada técnica del irlandés James Joyce y del norteamericano William Faulkner.

Dentro de la literatura comparada, uno de los asuntos menos estudiados es la influencia inter-hispanoamericana. En Guatemala, la primera indicación de esa influencia se vio cuando Martínez Sobral, aunque conocía las obras de Zola, fue estimulado por e' mexicano Federico Gamboa a aplicar el naturalismo a la realidad de su propio país. Las mismas obras de Gamboa le aguijonearon a la vez que le proporcionaron algunos detalles para sus argumentos.

Debilitada la hegemonía cultural de Europa con la Primera Guerra Mundial, muchos novelistas prefirieron buscar inspiración en las obras de dos contemporáneos americanos: José E. Rivera y Rómulo Gallegos. El efecto delirante de la naturaleza tropical, tan hábilmente retratado en La vorágine, dio ocasión a toda una serie de novelas selváticas. En Guatemala, el Petén hizo las veces de la selva colombiana en Anaité de Monteforte Toledo y en Carazamba de Rodríguez Macal. Carlos Wyld Ospina y Flavio Herrera supieron encontrar o simular condiciones semejantes en el llano costanero del Pacífico. Sin embatgo, en ninguna de esas cuatro obras se alcanzaron las proporciones épicas de La vorágine. Es lógico, Guatemala no tiene regiones ten salvajes como Colombia ni ha conocido la brutal explotación de los caucheros. Frente a la violencia de Rivera, se opone la civilización de Gallegos en las mismas obras de Wyld, Herrera y Monteforte, pero triunfa siempre la barbarie. En $E l$ solar de los Gonzagas, se nota también el influjo de Gallegos con el problema del terrateniente venido a menos que tiene que rehacer su vida adoptando una actiud menos intransigente. En Amor y cascajo de Leopoldo Zeissig, la civilización triunfa sobre la barbarie aunque la contienda no es muy difícil. Fuera de Rivera y Gallegos, los otros novelistas hispanoamericanos han actuado muy poco para con Guatemala. La protesta social y el estilo fragmentario de las novelas de la Revolución Mexicana fueron remedados por Carlos Manuel Pellecer en Llamarada en la montaña a la vez que El mundo es ancho y ajeno de Ciro Alegría sugitió el tema de la comunidad indigena a Rafael Zea Ruano para Tierra nuestra.

A pesar de que la novela guatemalteca ha absorbido todas estas in- 
fluencias, ha desarrollado algunos rasgos netamente suyos que, en conjunto, la hacen inconfundible con la de los otros países hispanoameticanos. Una de las peculiaridades de los novelistas guatemaltecos es su afán de experimentar y de ahí sus dos extremos: obras geniales y obras desequilibradas. Esa experimentación ha sido, en gran parte, responsable de la continua evolución de varios autores, pero también ha causado un gran desorden en lo tocante a la determinación de géneros. En los casos muy famosos de Irisarri, José Milla, Arévalo Martínez, Flavio Herrera, Miguel Ángel Asturias, Monteforte y David Vela, el espíritu experimental se aplica a la lengua y se manifiesta en juegos de palabras, discusiones etimológicas, nombres acuñados artifi. cialmente, valores auditivos, visuales y simbólicos, aún de las letras, y la creación de metáforas y símiles muy atrevidos. Una simple conjetura sobre el origen de este fenómeno es que la convivencia por más de cuatro siglos con los indios que siguen hablando su propio idioma ha despertado e intensificado el interés del autor guatemalteco por las sutilezas del castellano.

Otro rasgo de la novela que se puede achacar a la raza india es la introspección. Esa reconcentración interior se manifiesta en la novela al surgir monólogos en que el individuo torturado trata de analizar sus reacciones más íntimas frente a hechos reales. Sin embargo, es urgente advertir que esa característica no aparece hasta Arévalo Martínez y luego continúa con Brañas, Herrera, Asturias, Monteforte, Enrique Wyld y David Vela.

A causa de la vida interior de los personajes y de su contacto con la civilización indígena, otro rasgo muy fuerte de la novela guatemalteca de casi todas las épocas es la fantasía, que tiene diversos modos de manifestarse. El más aficionado de todos es Miguel Ángel Asturias. Una de sus obras fundamentales es Leyendas de Guatemala y en sus novelas mezcla muchos de los elementos legendarios de los maya-quichés con la realidad actual. Algunos de los espantos diabólicos que a continuación mencionamos aparecen en Don Bonifacio de Milla y en las novelas de Mencos Franco y de David Vela: el Sombrerón, el Duende, la Llorona, la Tatuana, el Cadejo y el Viejo. Hay visiones que podtían considerarse como alucinaciones en Stella y $U n$ peersonaje sin novela. El sueño tiene un papel importante en $A$ vista de pájaro y La volanda. En las novelas utópicas de Arévalo Martínez, las visiones son intelectuales en tanto que en Poniente de siremas y en Caos de Flavio Hierrera son esquizof rénicas. 
Como otra parte de su herencia india, los guatemaltecos no pueden escapar de la bistoria. Los monumentos arqueológicos les recuerdan constantemente la gloriosa civilización de sus antepasados. Sin embargo, Asturias y Monteforte son los únicos que han sabido transmitir ese sentimiento a la novela. En cambio, la novela histórica acerca de los tiempos coloniales ha sido cultivada por Milla, Mencos Franco, Soto. Hall, César Brañas, Juárez Muñoz, Elisa Hall y aun la hondureña Argentina Díaz Lozano, en parte porque éstos no querían arriesgarse a incurrir en la ira de varios dictadores iracundos.

Una relación que todavía no se ha afirmado bastante es la que exis. te literalmente entre los mismos novelistas guatemaltecos. Las huellas de José Milla se encuentran en las novelas históricas de Mencos Franco, Soto-Hall, Juárez Muñoz, Elisa Hall y en Con el alma a cuestas de En. rique Wyld. Este mismo libro también fue influido levemente por Irisarri y Arévalo Martínez. Irisarri, el primer guatemalteco que intentó escribir novelas, influyó sobre la última novela guatemalteca Un personaje sin novelt (1958). Marroquín Rojas y Flavio Herrera probablemente inspiraron, en parte, La brama de Hugo Salguero, de la misma manera que Anaité de Monteforte Toledo se contagió de lo delirante de El tigre y Dionde acaban los caminos, un poco más, del sicoanálisis del protagonista de Caros.

La influencia nacional es una de las señales de que la novela gua. temalteca ha llegado a su madurez. De aquí, ¿hacia dónde va? Igual que en todas partes de Hispanoamérica, el criollismo ya no está de moda. Si se puede percibir una nueva tendencia a esta proximidad, parece ser el universalismo, es decir, el desarraigar la novela de la tierra y tratar problemas de carácter universal. Sin embargo, es probable que los gua. temaltecos sigan sintiendo la influencia de las corrientes literarias del mundo, pero ya dueña de una tradición novelística, absorberá esas influencias y las adaptará conforme a su propio molde.

Seymour Menton.

Univarsidad de Kansas,

Lawrence, Kansas. 
